\title{
Profit Analysis of a Computer System with H/W Repair and S/W Replacement
}

\author{
S.C. Malik \\ Dept. of Statistics \\ M.D.University, Rohtak-124001
}

\author{
J.K.Sureria \\ Dept. of Statistics \\ M.D. University, Rohtak-124001 (India)
}

\begin{abstract}
The main intension of this paper is to make profit analysis of a computer system of two identical units in which one unit is operative and other is kept as cold standby. In each unit, $\mathrm{h} / \mathrm{w}$ and s/w components fail independently from the normal mode. A single server visits the system immediately whenever needed to carry out repair and replacement of the components. If there is $a \mathrm{~h} / \mathrm{w}$ failure in the unit, then that unit goes immediately under repair. However, only replacement of the $\mathrm{s} / \mathrm{w}$ in the unit is made by new one whenever s/w fails to meet out the requirements. The failure time of the unit is exponentially distributed while the distributions of repair rate of $h / w$ and replacement rate of the s/w are taken as arbitrary with different probability density functions (pdf). The expressions for several reliability characteristics are derived by making use of semi-Markov process and regenerative point technique. Graphs are drawn for a particular case to highlight the behaviour of some measures of system effectiveness. The results of the present model have also been compared with the results obtained for the model proposed by Malik and Anand [4].
\end{abstract}

\section{Keywords}

Computer System, Independent Failure of $\mathrm{H} / \mathrm{W}$ and $\mathrm{S} / \mathrm{W}$, Repair, Replacement and Profit Analysis.

2000 Mathematics Subject Classification: $90 B 25$ and $60 K 10$

\section{INTRODUCTION}

The increasing use of computers in all industrial sectors leads to the need to specify and design computing systems which could fulfil the requirements of the targeted applications at the lowest cost. Various requirements have to be taken into accounts whether functional (accuracy of the results and ease of use, etc.) or dependability requirements such as availability or maintainability. For that, a few researchers including Friedman and Tran [1] and Welke et al.[2] tried to develop a combined reliability model for the whole system including both $\mathrm{h} / \mathrm{w}$ and $\mathrm{s} / \mathrm{w}$. Lie et al. [3] developed a model for availability analysis of distributed $\mathrm{s} / \mathrm{w}$ and $\mathrm{h} / \mathrm{w}$ components. Recently, Malik and Anand [4] proposed a reliability model of a computer system with independent $\mathrm{h} / \mathrm{w}$ and $\mathrm{s} / \mathrm{w}$ failures considering repair of $\mathrm{h} / \mathrm{w}$ subject to inspection and replacement of $\mathrm{s} / \mathrm{w}$ components by new one with some replacement rate. It is a known fact that inspection is one of the best method to decide the feasibility of repair and replacement of the failed components in a system. But this increase the down time of the system and also some time replacement of the components by new one may be costly instead of repair. In such a situation repair of the failed components (or units) may be started immediately to enhanced the availability of the system and hence profit.
In view of the above observations and facts, here we analyse a computer system of two identical units in which each unit has independent complete failure of $\mathrm{h} / \mathrm{w}$ and $\mathrm{s} / \mathrm{w}$ components from normal mode. Initially one unit is operative and other is kept as cold standby. A single server is made available immediately to do repair of the $\mathrm{h} / \mathrm{w}$ and making replacement of the $\mathrm{s} / \mathrm{w}$. If operative unit is failed due to $\mathrm{h} / \mathrm{w}$, then it goes immediately under repair. However, replacement of the $\mathrm{s} / \mathrm{w}$ component in the unit is made by new one instead of repair whenever $\mathrm{s} / \mathrm{w}$ fails to meet out the requirements. The random variables are statistically independent and uncorrelated to each other. The switch devices and repairs are perfect. The failure time of the unit due to failure of $h / w$ and $s / w$ components are distributed exponentially while the distributions of replacement and repair rates are taken as arbitrary. To carry out the profit analysis, the numerical results for mean sojourn times, mean time to system failure (MTSF), availability, busy period of the server due to $\mathrm{h} / \mathrm{w}$ repair and replacement of the $\mathrm{s} / \mathrm{w}$ components, expected number of replacements due to $\mathrm{s} / \mathrm{w}$ failures and expected number of visits by the server are obtained using semi-Markov process and regenerative point technique. The graphs for a particular case are drawn to depict the behaviour of MTSF, availability and profit of the system model. The comparison of the results has also been made with the results obtained for the model proposed by Malik and Anand [4][2010]

\section{NOTATIONS}

$\begin{array}{lll}\mathrm{E} & : & \text { The set of regenerative states } \\ \mathrm{O} & : & \text { The unit is operative and in normal } \\ & & \text { mode } \\ \mathrm{Cs} & : & \text { The unit is cold standby } \\ \lambda_{1} / \lambda_{2} & : & \text { Constant hardware / software } \\ & & \text { failure rate }\end{array}$

FHUr/FHUR : The unit is failed due to hardware and is under repair / under repair continuously from previous state

FHWr /FHWR :The unit is failed due to hardware and is waiting for repair/waiting for repair continuously from previous state

FSURp/FSURP: The unit is failed due to the software and is under replacement/ under replacement continuously 
from previous state

FSWRp/FSWRP: The unit is failed due to the software and is waiting for replacement / waiting for replacement continuously from previous state

$\mathrm{f}(\mathrm{t}) / \mathrm{F}(\mathrm{t})$ : pdf / cdf of replacement time of the software

$\mathrm{g}(\mathrm{t}) / \mathrm{G}(\mathrm{t})$ : pdf / cdf of repair time of the unit due to hardware failure

$\mathrm{q}_{\mathrm{ij}}(\mathrm{t}) / \mathrm{Q}_{\mathrm{ij}}(\mathrm{t})$ :pdf / cdf of passage time from regenerative state $i$ to a regenerative state $\mathrm{j}$ or to a failed state $\mathrm{j}$ without visiting any other regenerative state in $(0, \mathrm{t}]$

$\mathrm{q}_{\mathrm{ij} . k r}(\mathrm{t}) / \mathrm{Q}_{\mathrm{ij.kr}}(\mathrm{t})$ :pdf/cdf of direct transition time from regenerative state $i$ to a regenerative state $\mathrm{j}$ or to a failed state $\mathrm{j}$ visiting state $\mathrm{k}, \mathrm{r}$ once in $(0, t]$

$\mathrm{m}_{\mathrm{ij}} \quad$ : Contribution to mean sojourn time $\left(\mu_{\mathrm{i}}\right)$ in state $S_{\mathrm{i}}$ when system transit directly to state $\mathrm{S}_{\mathrm{j}}$ so that $\mu_{i}=\sum_{j} m_{i j}$ and $\mathrm{m}_{\mathrm{ij}}=\int t d Q_{i j}(t)=-q_{i j}^{*^{\prime}}(0)$

(S)(C) : Symbol for Laplace-Stieltjes convolution/Laplace convolution

$\sim /^{*}$ : Symbol for Laplace Steiltjes Transform

(LST) / Laplace Transform (LT)

' (desh): Used to represent alternative result

The following are the possible transition states of the system:

$\mathrm{S}_{0}=(\mathrm{O}, \mathrm{Cs})$

$\mathrm{S}_{1}=(\mathrm{O}, \mathrm{FHUr})$,

$\mathrm{S}_{2}=(\mathrm{O}$,

FSURp),

$\mathrm{S}_{3}=($ FHUR, FHWr $), \quad \mathrm{S}_{4}=($ FHUR, FSWRp $), \quad \mathrm{S}_{5}=$ (FSURP, FSWRp),

$\mathrm{S}_{6}=($ FHWr, FSURP)

The states $S_{0}-S_{2}$ are regenerative states while the states $S_{3}-S_{6}$ are non-regenerative as shown in figure 1 .

\section{RELIABILITY INDICES}

\subsection{Transition Probabilities and Mean} Sojourn Times

Simple probabilistic considerations yield the following expressions for the non-zero elements

$$
p_{i j}=Q_{i j}(\infty)=\int_{0}^{\infty} q_{i j}(t) d t \text { as }
$$

$$
\begin{aligned}
& \mathrm{p}_{01}=\frac{a \lambda_{1}}{a \lambda_{1}+b \lambda_{2}}, \quad \mathrm{p}_{02}=\frac{b \lambda_{2}}{a \lambda_{1}+b \lambda_{2}}, \\
& \mathrm{p}_{10}=g *\left(a \lambda_{1}+b \lambda_{2}\right),
\end{aligned}
$$$$
\mathrm{p}_{13}=\frac{a \lambda_{1}}{a \lambda_{1}+b \lambda_{2}}\left[1-g *\left(a \lambda_{1}+b \lambda_{2}\right)\right] \text {, }
$$$$
\mathrm{p}_{14}=\frac{b \lambda_{2}}{a \lambda_{1}+b \lambda_{2}}\left[1-g *\left(a \lambda_{1}+b \lambda_{2}\right)\right] \text {, }
$$$$
\mathrm{p}_{20}=f *\left(a \lambda_{1}+b \lambda_{2}\right) \text {, }
$$$$
\mathrm{p}_{25}=\frac{b \lambda_{2}}{a \lambda_{1}+b \lambda_{2}}\left[1-f *\left(a \lambda_{1}+b \lambda_{2}\right)\right],
$$

$=\frac{a \lambda_{1}}{a \lambda_{1}+b \lambda_{2}}\left[1-f *\left(a \lambda_{1}+b \lambda_{2}\right)\right]$,

$\mathrm{p}_{31}=g *(s), \quad \mathrm{p}_{42}=g *(s)$,

$$
\mathrm{p}_{52}=f *(s), \quad \mathrm{p}_{61}=f *(s)
$$

For $\mathrm{f}(\mathrm{t})=\theta e^{-\theta t}$ and $\mathrm{g}(\mathrm{t})=\alpha e^{-\alpha t}$ we have

$\mathrm{p}_{11.3}=\frac{a \lambda_{1}}{a \lambda_{1}+b \lambda_{2}+\alpha}, \mathrm{p}_{12.4}=\frac{b \lambda_{2}}{a \lambda_{1}+b \lambda_{2}+\alpha}$

$\mathrm{p}_{21.6}=\frac{a \lambda_{1}}{a \lambda_{1}+b \lambda_{2}+\theta}, \mathrm{p}_{22.5}=\frac{b \lambda_{2}}{a \lambda_{1}+b \lambda_{2}+\theta}$

It can be easily verified that $\mathrm{p}_{01}+\mathrm{p}_{02}=\mathrm{p}_{10}+\mathrm{p}_{13}+\mathrm{p}_{14}=$ $\mathrm{p}_{20}+\mathrm{p}_{25}+\mathrm{p}_{26}=\mathrm{p}_{31}=\mathrm{p}_{42}=\mathrm{p}_{52}=\mathrm{p}_{61}=\mathrm{p}_{10}+\mathrm{p}_{11.3}+\mathrm{p}_{12.4}=$ $\mathrm{p}_{20}+\mathrm{p}_{21.6}+\mathrm{p}_{22.5}=1$

The mean sojourn times $\left(\mu_{\mathrm{i}}\right)$ is the state $S_{\mathrm{i}}$ are

$\mu_{0}=\frac{1}{a \lambda_{1}+b \lambda_{2}}, \mu_{1}=\frac{1}{a \lambda_{1}+b \lambda_{2}+\alpha}$,

$\mu_{2}=\frac{1}{a \lambda_{1}+b \lambda_{2}+\theta}$

Also

$m_{01}+m_{02}=\mu_{0}, m_{10}+m_{13}+m_{14}=\mu_{1}$,

$m_{20}+m_{25}+m_{26}=\mu_{2}$

And

$m_{10}+m_{11.2}+m_{12.4}=\mu_{1}^{\prime}$ (Say) 
$m_{20}+m_{21.6}+m_{22.5}=\mu_{2}^{\prime}$ (Say)

For $f(\mathrm{t})=\theta e^{-\theta t}$ and $\mathrm{g}(\mathrm{t})=\alpha e^{-\alpha t}$, we have

\subsection{Reliability and Mean Time to System Failure (MTSF)}

Let $\phi_{\mathrm{i}}(\mathrm{t})$ be the c.d.f. of first passage time from regenerative state $\mathrm{i}$ to a failed state. Regarding the failed state as absorbing state, we have the following recursive relations for $\phi_{i}(\mathrm{t})$ :

$$
\begin{aligned}
& \phi_{0}(\mathrm{t})=\mathrm{Q}_{01}(\mathrm{t}) \subseteq \phi_{1}(\mathrm{t})+\mathrm{Q}_{02}(\mathrm{t}) \subseteq \phi_{2}(\mathrm{t}) \\
& \phi_{1}(\mathrm{t})=\mathrm{Q}_{10}(\mathrm{t}) \subseteq \phi_{0}(\mathrm{t})+\mathrm{Q}_{13}(\mathrm{t})+\mathrm{Q}_{14}(\mathrm{t}) \\
& \phi_{2}(\mathrm{t})=\mathrm{Q}_{20}(\mathrm{t}) \subseteq \phi_{0}(\mathrm{t})+\mathrm{Q}_{25}(\mathrm{t})+\mathrm{Q}_{26}(\mathrm{t})
\end{aligned}
$$

Taking LST of above relation (8) and solving for $\tilde{\phi}_{0}(s)$

We have

$\mathrm{R} *(\mathrm{~s})=\frac{1-\widetilde{\phi}_{0}(s)}{s}$

The reliability of the system model can be obtained by taking Laplace inverse transform of (9).

Where $\mathrm{M}_{\mathrm{i}}(\mathrm{t})$ is the probability that the system is up initially in state $S_{i} \in E$ is up at time $\mathrm{t}$ without visiting to any other regenerative state, we have

$$
\begin{aligned}
& M_{0}(t)=e^{-\left(a \lambda_{1}+b \lambda_{2}\right) t}, M_{1}(t)=e^{-\left(a \lambda_{1}+b \lambda_{2}\right) t} \bar{G}(t), \\
& M_{2}(t)=e^{-\left(a \lambda_{1}+b \lambda_{2}\right) t} \bar{F}(t)
\end{aligned}
$$

Taking LT of above relations (11) and solving for $A_{0}^{*}(s)$, the steady state availability is given by

$$
A_{0}(\infty)=\lim _{s \rightarrow 0} s A_{0}^{*}(s)=\frac{N_{2}}{D_{2}}
$$

where

$\mathrm{N}_{2}=\left(\mathrm{p}_{10} \mathrm{p}_{20}+\mathrm{p}_{10} \mathrm{p}_{21.6+} \mathrm{p}_{20} \mathrm{p}_{12.4)} \mu_{0}+\left(\mathrm{p}_{01} \mathrm{p}_{20}+\mathrm{p}_{21.6}\right) \mu_{1}+\left(\mathrm{p}_{10} \mathrm{p}_{02+}\right.\right.$ $\mathrm{p}_{12.4)} \mu_{2}$

And

$\mathrm{D}_{2}=\left(\mathrm{p}_{10} \mathrm{p}_{20}+\mathrm{p}_{10} \mathrm{p}_{21.6+} \mathrm{p}_{20} \mathrm{p}_{12.4)} \mu_{0}+\left(\mathrm{p}_{01} \mathrm{p}_{20}+\mathrm{p}_{21.6}\right) \mu_{1}^{\prime}+\left(\mathrm{p}_{10}\right.\right.$

$\left.\mathrm{p}_{02+} \mathrm{p}_{12.4}\right) \mu_{2}^{\prime}$

$$
\mu_{1}^{1}=\frac{1}{\alpha}, \quad \mu_{2}^{1}=\frac{1}{\theta}
$$

The mean time to system failure (MTSF) is given by $\mathrm{MTSF}=\lim _{s \rightarrow o} \frac{1-\tilde{\phi}_{0}(s)}{s}=\frac{N_{1}}{D_{1}}$

where

$\mathrm{N}_{1}=\mu_{0}+p_{01} \mu_{1}+p_{02} \mu_{2}$

$\mathrm{D}_{1}=1-p_{01} p_{10}-p_{02} p_{20}$

\subsection{Steady State Availability}

Let $A_{i}(t)$ be the probability that the system is in up-state at instant ' $\mathrm{t}$ ' given that the system entered regenerative state $i$ at $t$ $=0$. The recursive relations for $\mathrm{A}_{\mathrm{i}}(\mathrm{t})$ are given as

$$
\begin{array}{ll}
\mathrm{A}_{0}(\mathrm{t})= & \mathrm{M}_{0}(\mathrm{t})+\mathrm{q}_{01}(\mathrm{t}) \odot \mathrm{A}_{1}(\mathrm{t})+\mathrm{q}_{02}(\mathrm{t}) \odot \mathrm{A}_{2}(\mathrm{t}) \\
\mathrm{A}_{1}(\mathrm{t})= & \mathrm{M}_{1}(\mathrm{t})+\mathrm{q}_{10}(\mathrm{t}) \odot \mathrm{A}_{0}(\mathrm{t})+\mathrm{q}_{11.3}(\mathrm{t}) \odot \mathrm{A}_{1}(\mathrm{t})+\mathrm{q}_{12.4}(\mathrm{t}) \odot \\
& \mathrm{A}_{2}(\mathrm{t}) \\
\mathrm{A}_{2}(\mathrm{t})= & \mathrm{M}_{2}(\mathrm{t})+\mathrm{q}_{20}(\mathrm{t}) \odot \mathrm{A}_{0}(\mathrm{t})+\mathrm{q}_{21.6}(\mathrm{t}) \odot \mathrm{A}_{1}(\mathrm{t})+\mathrm{q}_{22.5}(\mathrm{t}) \odot \\
& \mathrm{A}_{2}(\mathrm{t})
\end{array}
$$

Let $B_{i}^{H}(t)$ be the probability that the server is busy in repairing the unit due to hardware failure at an instant ' $\mathrm{t}$ ' given that the system entered state $\mathrm{i}$ at $\mathrm{t}=0$. The recursive relations $B_{i}^{H}(t)$ for are as follows:

$$
\begin{aligned}
& B_{0}^{H}(\mathrm{t})\left(\mp \mathrm{q} \mathrm{p}_{1}(\mathrm{t}) \odot B_{1}^{H}(\mathrm{t})+\mathrm{q}_{02}(\mathrm{t}) \odot B_{2}^{H}(\mathrm{t})\right. \\
& B_{1}^{H}(\mathrm{t})=W_{1}^{H}(\mathrm{t})+\mathrm{q}_{10}(\mathrm{t}) \odot B_{0}^{H}(\mathrm{t})+\mathrm{q}_{11.3}(\mathrm{t}) \odot B_{1}^{H}(\mathrm{t})+ \\
& \mathrm{q}_{12.4}(\mathrm{t}) \odot B_{2}^{H}(\mathrm{t}) \\
& B_{2}^{H}(\mathrm{t})=\mathrm{q}_{20}(\mathrm{t}) \odot B_{0}^{H}(\mathrm{t})+\mathrm{q}(1,16 \mathrm{l}) \odot B_{1}^{H}(\mathrm{t})+\mathrm{q}_{22.5}(\mathrm{t}) \\
& \odot B_{2}^{H}(\mathrm{t})
\end{aligned}
$$

Where $\mathrm{W}_{\mathrm{i}}^{\mathrm{H}}(\mathrm{t})$ be the probability that the server is busy in state $S_{i}$ due to hardware failure up to time $t$ without making any transition to any other regenerative state or returning to the same via one or more non-regenerative states and so

$$
\begin{aligned}
W_{1}^{H}= & e^{-\left(a \lambda_{1}+b \lambda_{2}\right) t} \overline{\mathrm{G}}(t)+\left(a \lambda_{1} e^{-\left(a \lambda_{1}+b \lambda_{2}\right) t} \mathrm{C} 1\right) \\
& \overline{\mathrm{G}}(t)+\left(b \lambda_{2} e^{-\left(a \lambda_{1}+b \lambda_{2}\right) t} \mathrm{C} 1\right) \overline{\mathrm{G}}(t) \ldots(15)
\end{aligned}
$$

\subsection{Busy Period Analysis for Server}




\subsubsection{Due to replacement of the software}

Let $B_{i}^{S}$ (t) be the probability that the server is busy due to replacement of the software at an instant ' $t$ ' given that the system entered the regenerative state $\mathrm{i}$ at $\mathrm{t}=0$. We have the following recursive relations for $B_{i}^{S}(\mathrm{t})$ :

$$
\begin{aligned}
& B_{0}^{S}(\mathrm{t})=\mathrm{q}_{01}(\mathrm{t}) \odot B_{1}^{S}(\mathrm{t})+\mathrm{q}_{02}(\mathrm{t}) \odot B_{2}^{S}(t) \\
& B_{1}^{S}(t)=\mathrm{q}_{10}(\mathrm{t}) \odot B_{0}^{S}(\mathrm{t})+\mathrm{q}_{11.3}(\mathrm{t}) \odot B_{1}^{S}(\mathrm{t})+ \\
& \\
&\left.\mathrm{q}_{12.4}(\mathrm{t})\right) \odot B_{2}^{S}(t) \\
& B_{2}^{S}(t)=W_{2}^{S}(t)+\mathrm{q}_{20}(\mathrm{t}) \odot B_{0}^{S}(\mathrm{t})+\mathrm{q}_{21.6}(\mathrm{t}) \odot \\
& B_{1}^{S}(\mathrm{t})+\mathrm{q}_{22.5}(\mathrm{t}) \odot B_{2}^{S}(t)
\end{aligned}
$$

where $W_{i}^{S}$ (t) be the probability that the server is busy in state $S_{i}$ due to replacement of the software up to time $t$ without making any transition to any other regenerative state or returning to the same via one or more non-regenerative states and so

$$
\begin{aligned}
W_{2}^{S}(t)= & e^{-\left(a \lambda_{1}+b \lambda_{2}\right) t} \bar{F}(t)+\left(a \lambda_{1} e^{-\left(a \lambda_{1}+b \lambda_{2}\right) t} \mathrm{C} 1\right) \\
& \bar{F}(t)+\left(b \lambda_{2} e^{-\left(a \lambda_{1}+b \lambda_{2}\right) t} \text { C } 1\right) \bar{F}(t) \ldots . .(17)
\end{aligned}
$$

Taking L.T. of above relations (14) and (16). And, solving for $B_{0}^{*^{H}}$ (s) and $B_{0}^{*^{s}}$ (s), the time for which server is busy due to repair and replacements respectively is given by

$$
B_{0}^{H}=\lim _{s \rightarrow 0} s B_{0}^{* H}(s)=\frac{N_{3}^{H}}{D_{2}}
$$

And

$$
B_{0}^{S}=\lim _{s \rightarrow 0} s B_{0}^{* S}(s)=\frac{N_{3}^{S}}{D_{2}}
$$

where

$$
N_{3}^{H}=\tilde{W}_{1}^{H}(s)\left[p_{01} p_{20}+p_{21.6}\right]
$$$$
N_{3}^{S}=\left(p_{10} p_{02}+p_{12.4}\right) \tilde{W}_{2}^{S}(s)
$$

And $\mathrm{D}_{2}$ is already mentioned.

\subsection{Expected Number of Replacements of the Units Due to Software Failure}

Let $R_{i}^{S}(t)$ be the expected number of replacements of the failed software by the server in $(0, t]$ given that the system entered the regenerative state $i$ at $t=0$. The recursive relations for $R_{i}^{S}(t)$ are given as

$$
\begin{aligned}
R_{0}^{S}(t)= & \mathrm{Q}_{01}(\mathrm{t}) \subseteq R_{1}^{S}(t)+\mathrm{Q}_{02}(\mathrm{t}) \subseteq R_{2}^{S}(t) \\
R_{1}^{S}(t)= & \mathrm{Q}_{10}(\mathrm{t}) \subseteq R_{0}^{S}(t)+\mathrm{Q}_{11.3}(\mathrm{t}) \subseteq R_{1}^{S}(t)+ \\
& \mathrm{Q}_{12.4}(\mathrm{t}) \subseteq R_{2}^{S}(t) \\
R_{2}^{S}(t)= & \mathrm{Q}_{20}(\mathrm{t}) \subseteq\left[1+R_{0}^{S}(t)\right]+\mathrm{Q}_{21.6}(\mathrm{t}) \subseteq[1+ \\
& \left.R_{1}^{S}(t)\right]+\mathrm{Q}_{22.5}(\mathrm{t}) \subseteq\left[1+R_{2}^{S}(t)\right] \ldots . .(18)
\end{aligned}
$$

Taking L.S.T. of relations (18). And, solving for $\widetilde{R}_{0}^{S}(s)$. The expected numbers of replacements per unit time to the hardware and software failures are given by

$$
R_{0}^{S}(\infty)=\lim _{s \rightarrow 0} s \tilde{R}_{0}^{S}(s)=\frac{N_{4}^{S}}{D_{2}}
$$

where

$$
N_{4}^{S}=p_{02} p_{10}+p_{12.4}
$$

And $\mathrm{D}_{2}$ is already mentioned.

\subsection{Expected Number of Visits by the Server}

Let $\mathrm{N}_{\mathrm{i}}(\mathrm{t})$ be the expected number of visits by the server in $(0, t]$ given that the system entered the regenerative state $i$ at $t$ $=0$. The recursive relations for $\mathrm{N}_{\mathrm{i}}(\mathrm{t})$ are given as

$$
\begin{aligned}
& \mathrm{N}_{0}(\mathrm{t})=\mathrm{Q}_{01}(\mathrm{t})\left(5\left[1+\mathrm{N}_{1}(\mathrm{t})\right]+\mathrm{Q}_{02}(\mathrm{t}) \text { (S) }\left[1+\mathrm{N}_{2}(\mathrm{t})\right]\right. \\
& \mathrm{N}_{1}(\mathrm{t})=\mathrm{Q}_{10}(\mathrm{t})\left(S \mathrm{~N}_{0}(\mathrm{t})+\mathrm{Q}_{11.3}(\mathrm{t})(\mathrm{d}) \mathrm{P}_{1}(\mathrm{t})+\mathrm{Q}_{12.4}(\mathrm{t})\right. \\
& \text { (S) } \mathrm{N}_{2}(\mathrm{t}) \\
& \mathrm{N}_{2}(\mathrm{t})=\mathrm{Q}_{20}(\mathrm{t})\left(S \mathrm{~N}_{0}(\mathrm{t})+\mathrm{Q}_{21.6}(\mathrm{t})\left(\mathrm{S} N 2(\mathrm{t})+\mathrm{Q}_{22.5}(\mathrm{t})\right.\right. \\
& \text { (S) } \mathrm{N}_{2}(\mathrm{t})
\end{aligned}
$$

Taking LST of relation (19) and solving for $\tilde{N}_{0}(s)$. The expected number of visits per unit time by the server is given by

$$
N_{0}(\infty)=\lim _{s \rightarrow 0} s \tilde{N}_{0}(s)=\frac{N_{5}}{D_{2}}
$$

where

$\mathrm{N}_{5}=\mathrm{p}_{10} \mathrm{p}_{20}+\mathrm{p}_{20} \mathrm{p}_{12.4}+\mathrm{p}_{10} \mathrm{p}_{21.6}$

And $\mathrm{D}_{2}$ is already specified. 


\subsection{Economic Analysis}

The profit incurred to the system model in steady state can be obtained as

$\mathrm{P}=K_{0} A_{0}-K_{1} B_{0}^{H}-K_{2} B_{0}^{S}-K_{3} R_{0}^{S}-K_{4} N_{0}$

where

$\mathrm{K}_{0}=$ Revenue per unit up-time of the system

$\mathrm{K}_{1}=$ Cost per unit time for which server is busy due to hardware failure

$\mathrm{K}_{2}=$ Cost per unit time for which server is busy due to software failure

$\mathrm{K}_{3}=$ Cost per unit replacement of the failed software

$\mathrm{K}_{4}=$ Cost per unit visit by the server and $A_{0}, B_{0}^{H}, B_{0}^{S}, R_{0}^{S}, N_{0}$ are already defined.

\subsection{Particular Case}

Suppose $g(t)=a e^{-a t}, f(t)=\theta e^{-\theta t}$

We can obtain the following results

$\operatorname{MTSF}\left(\mathrm{T}_{0}\right)=\frac{N_{1}}{D_{1}}, \quad$ Availability $\left(\mathrm{A}_{0}\right)=\frac{N_{2}}{D_{2}}$

Busy period due to hardware failure $\left(B_{0}^{H}\right)=\frac{N_{3}^{H}}{D_{2}}$

Busy period due to software failure $\left(B_{0}^{S}\right)=\frac{N_{3}^{S}}{D_{2}}$

Expected number of replacements at software failure $\left(R_{0}^{S}\right)=\frac{N_{4}^{S}}{D_{2}}$, where

\section{CONCLUSION}

In the present study, the numerical results considering particular values to the parameters are obtained to carry out the profit analysis of a computer system with repair of $h / w$ and replacement of $\mathrm{s} / \mathrm{w}$ components. The graphs for mean time to system failure (MTSF), availability and profit are drawn with respect to $\mathrm{h} / \mathrm{w}$ failure rate $\left(\lambda_{1}\right)$ for the fixed values of other parameters as shown in figures 2, 3 and 4 respectively. It is observed that MTSF goes on increasing when $\mathrm{h} / \mathrm{w}$ repair rate $(\alpha)$ and $\mathrm{s} / \mathrm{w}$ replacement rate $(\theta)$ increase with $a=0.7$ and $b=0.3$. And, it becomes more if we interchange the values of a and $b$. However, the value of MTSF decreases with the increase of $\mathrm{h} / \mathrm{w}$ and $\mathrm{s} / \mathrm{w}$ failure rates.

Figures 2 and 3 indicate that availability and profit decrease with the increase of $\mathrm{h} / \mathrm{w}$ and $\mathrm{s} / \mathrm{w}$ failure rates $\lambda 1$ and $\lambda 2$ for $a=0.7$ and $b=0.3$. But, their values increase with the increase of repair rate $(\theta)$ and replacement rate $(\alpha)$. It is also observed that when the values of $\mathrm{a}$ and $\mathrm{b}$ are interchanged, the system becomes more profitable for $\lambda 1>0.01$.

$$
N_{1}=\frac{b \lambda_{2}\left(a \lambda_{1}+b \lambda_{2}+\alpha\right)}{R_{1}}
$$$$
R_{1}=\left(a \lambda_{1}+b \lambda_{2}\right)\left(a \lambda_{1}+b \lambda_{2}+\theta\right)\left(a \lambda_{1}+b \lambda_{2}+\alpha\right)
$$$$
\left(a \lambda_{1}+2 b \lambda_{2}+\theta\right)\left(a \lambda_{1}+b \lambda_{2}+\alpha\right)\left(a \lambda_{1}+b \lambda_{2}\right)-
$$$$
D_{1}=\frac{a \lambda_{1} \alpha\left(a \lambda_{1}+b \lambda_{2}+\theta\right)-b \lambda_{2} \theta\left(a \lambda_{1}+b \lambda_{2}+\alpha\right)}{R_{1}}
$$$$
\alpha \theta\left(a \lambda_{1} \alpha+b \lambda_{2} \theta+\alpha \theta\right)+\left(a \lambda_{1} \theta+b \lambda_{2} \alpha\right)
$$$$
D_{2}=\frac{\left(a \lambda_{1}+b \lambda_{2}+\alpha\right)\left(a \lambda_{1}+b \lambda_{2}+\theta\right)}{\alpha \theta R_{1}}
$$$$
N_{2}=\frac{\left(a \lambda_{1}+b \lambda_{2}+\theta\right)\left(a \lambda_{1}+b \lambda_{2}+\alpha\right)}{R_{1}},
$$$$
N_{3}^{H}=\frac{a \lambda_{1}\left(a \lambda_{1}+b \lambda_{2}+\theta\right)\left(a \lambda_{1}+b \lambda_{2}+\alpha\right)}{\alpha R_{1}}
$$$$
N_{3}^{S}=\frac{b \lambda_{2}\left(a \lambda_{1}+b \lambda_{2}+\alpha\right)\left(a \lambda_{1}+b \lambda_{2}+\theta\right)}{\theta R_{1}},
$$$$
N_{4}^{S}=\frac{b \lambda_{2}}{a \lambda_{1}+b \lambda_{2}},
$$$$
N_{5}=\frac{\alpha a \lambda_{1}+\theta\left(\alpha+b \lambda_{2}\right)}{\left(a \lambda_{1}+b \lambda_{2}+\theta\right)\left(a \lambda_{1}+b \lambda_{2}+\alpha\right)}
$$

\section{COMPARATIVE STUDY}

The concept of inspection is introduce in the model proposed by Malik and Anand [2010] to decide the feasibility of repair of a computer system at its $h / w$ failure. If repair of the $h / w$ component is not feasible to the system, it is replaced immediately by new one. But in the present model repair of the system at its $\mathrm{h} / \mathrm{w}$ failure is started immediately without getting inspection. The difference of MTSF and profit obtained for both the models are examined graphically as shown in figures 5 and 6 . Figure 5 shows that MTSF of the present model is less than that of the model Malik and Anand [2010]. However, if we increase $h / w$ repair rate $(\alpha)$ from 2.5 to 3.5, the MTSF of the present model becomes more. From figure 6 , it is analysed that present model is always profitable for $\lambda 1>0.03$. But we interchange the values of $a=0.7$ and $\mathrm{b}=0.3$, the model Malik and Anand [2010] becomes more profitable for $\lambda 1 \leq 0.03$.

Thus, on the basis of the results obtained for a particular case it is suggested that a computer system in which $\mathrm{h} / \mathrm{w}$ and $\mathrm{s} / \mathrm{w}$ components fails immediately can be made more reliable and profitable to use by repairing the $\mathrm{h} / \mathrm{w}$ components immediately with higher rates without conducting inspection. 


\section{ACKNOWLEDGEMENT}

The authors are grateful to the University Grants Commission (UGC) New Delhi,, India for providing financial Assistance to carry out this research work under Major Research Project.

\section{REFERENCES}

[1] Friedman, M.A. and Tran, P. (1992): Reliability techniques for combined hardware / software systems. Proceedings of Annual Reliability and Maintainability Symposium, pp. 209-293.

[2] Welke, S.R.; Johnson, B.W. and Aylar, J.H.(1995): Reliability modeling of hardware /software systems,
IEEE Transactions on Reliability, Vol. 44, No. 3, pp. 413-418.

[3] Lai, C.D.; Xie, M.; Poh, K.L.; Dai, Y.S. andYang, P. (2002): A Model for Availability Analysis of Distributed Software / Hardware Systems, Information and Software Technology, Vol. 44, pp. 343-350.

[4] Mailk, S.C and Anand, Jyoti (2010):Reliability and Economic Analysis Of a Computer System with Independent Hardware and SoftwareFailures. Bulletin of Pure and Applied Sciences.Vol.29E (No.1), pp.141153.

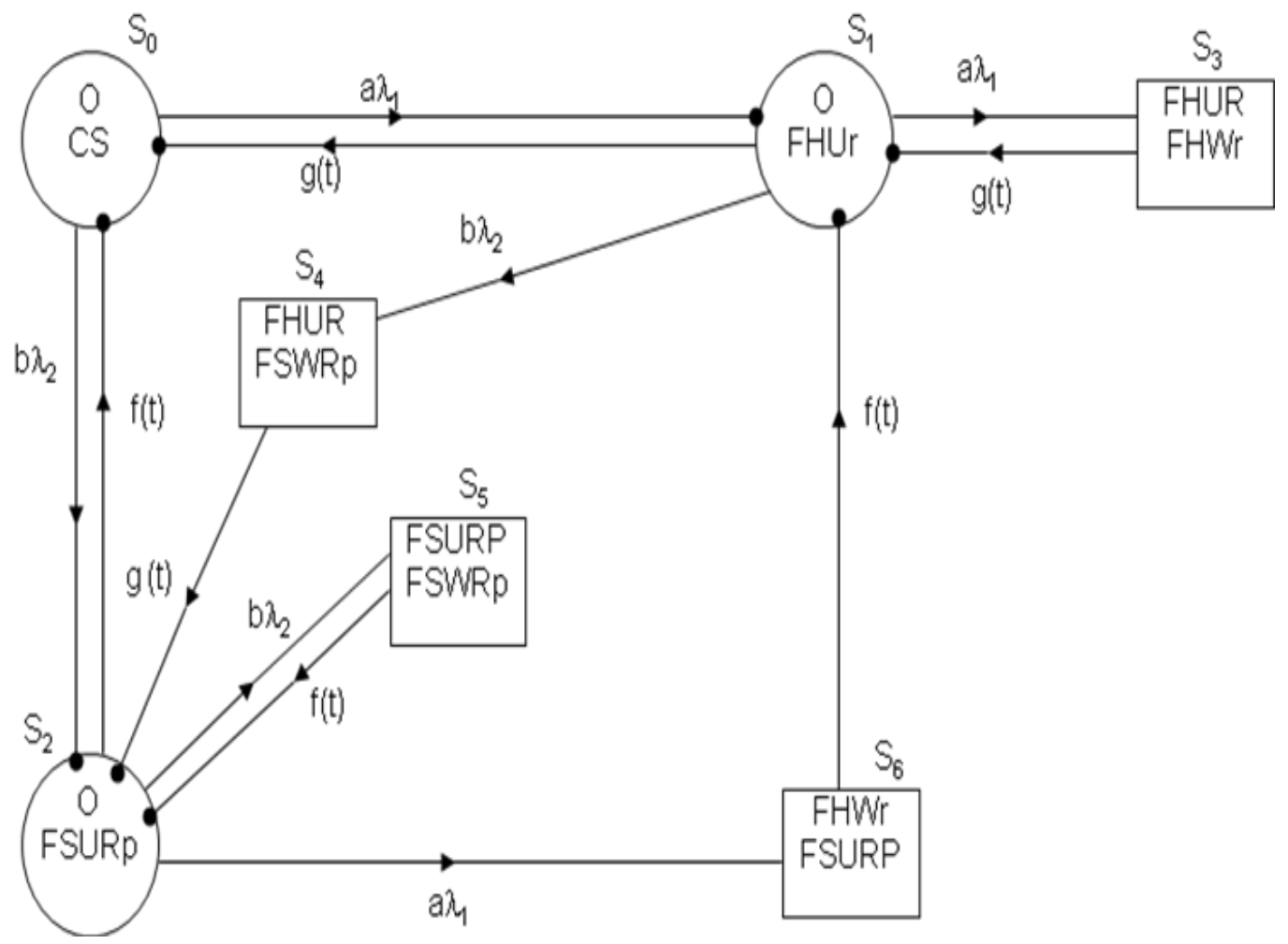

Fig. 1: State Transition Diagram

Up-state

Failed state

- Regenerative point 

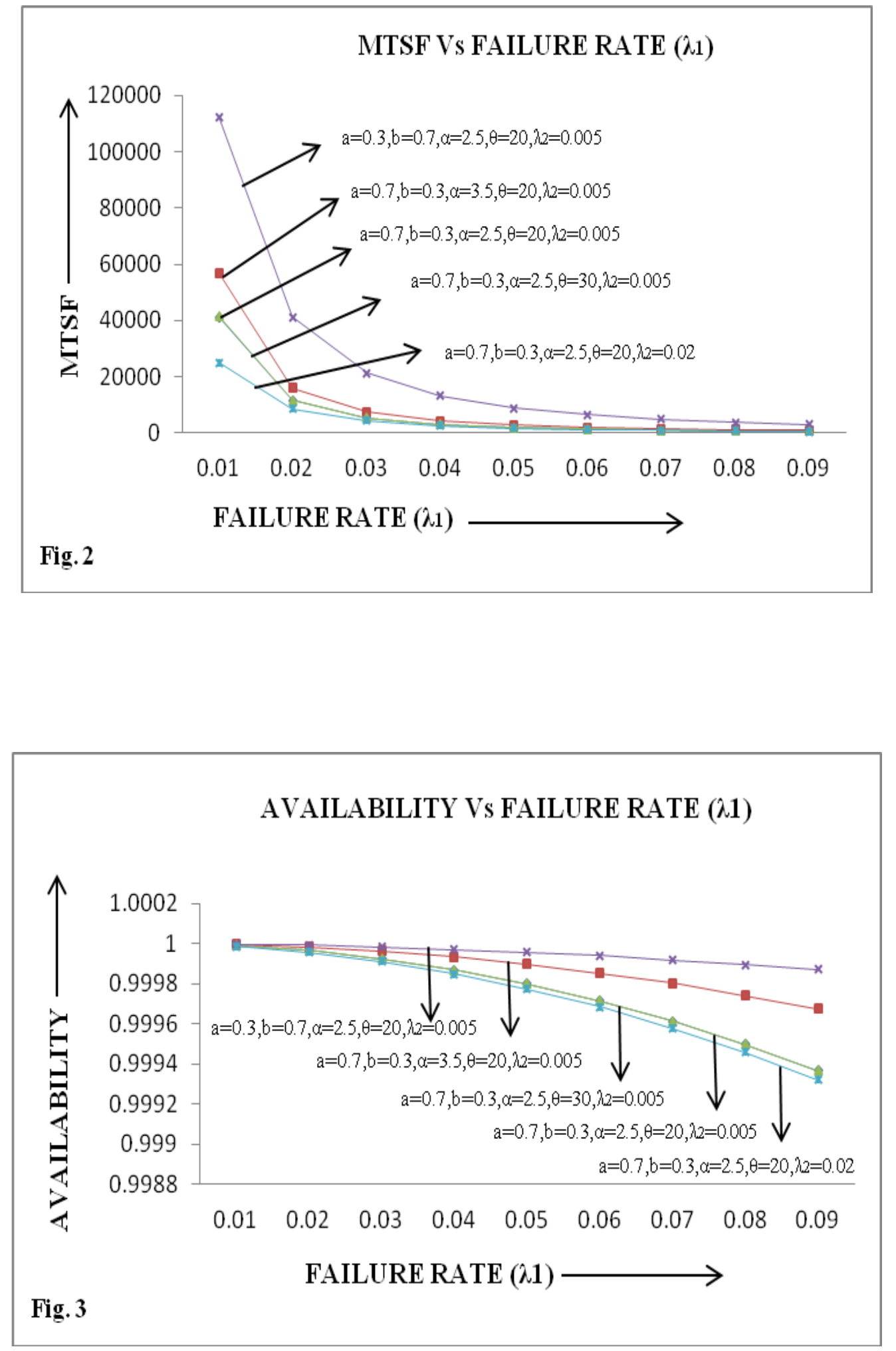

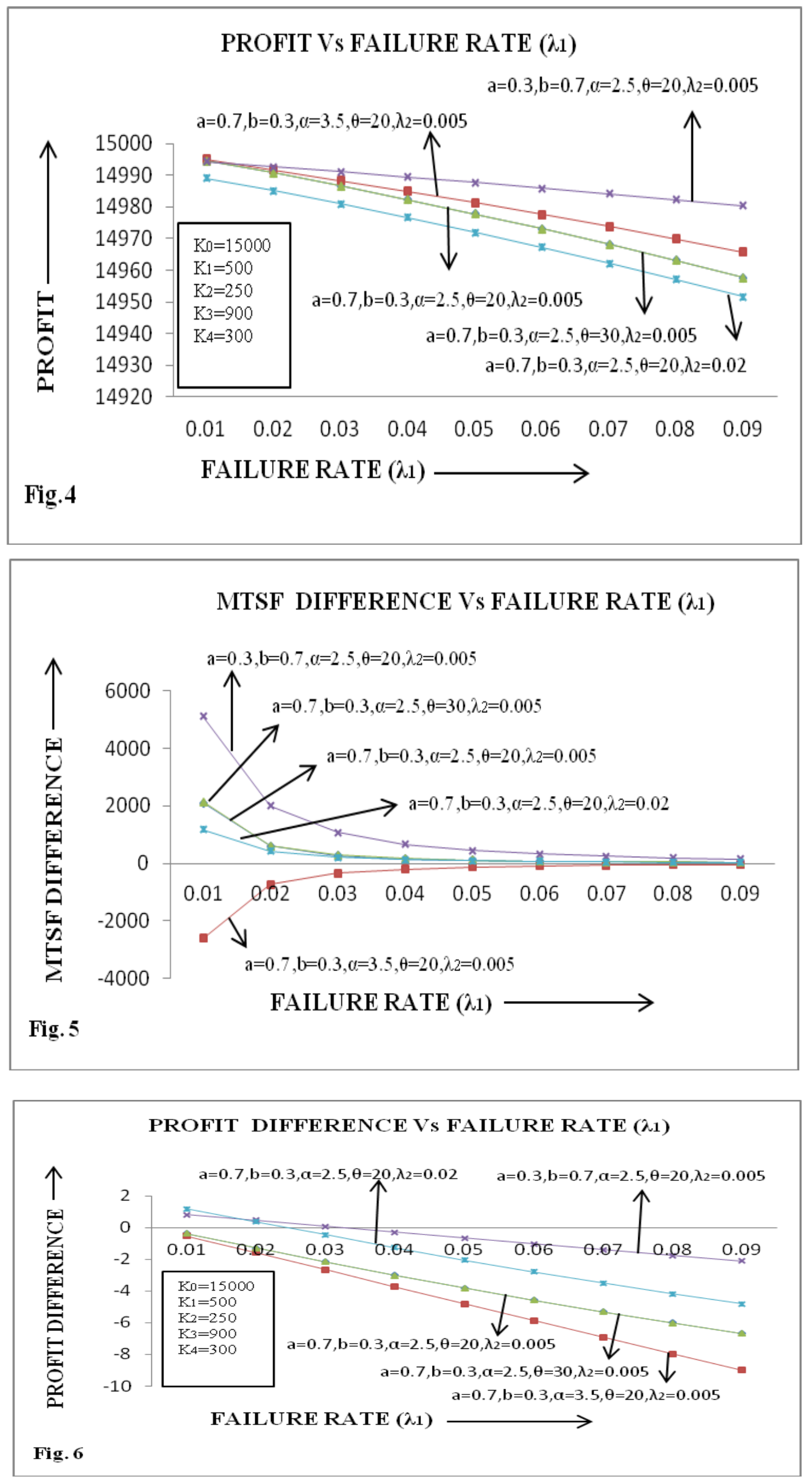